\title{
PERANAN GURU PKn DALAM MENINGKATKAN WAWASAN KEBANGSAAN DAN CINTA TANAH AIR (WANGSA CITA) DI ERA GLOBALISASI PADA SISWA SMA MUHAMMADIYAH 1 MALANG
}

\author{
Eka Nur Cahyaning Asih, Nurul Zuriah, Budiono \\ FKIP Universitas Muhammadiyah Malang \\ Email : ekanurcahyaning26@gmail.com
}

\begin{abstract}
ABSTRAK
Wawasan kebangsaan dan cinta tanah air melahirkan sebuah pemahaman, kesadaran, dan sikap dari elemen anak bangsa terhadap pilar kehidupan berbangsa dan bernegara dan menjadikan sebagai orientasi, perwujudan nilai dan tingkah sehari-hari. Melalui peranan guru PKn , pendidikan wangsa cita dapat tumbuh dan meningkat pada anak bangsa, karena guru PKn merupakan seseorang yang harus memiliki kemampuan mengelola pembelajaran peserta didik sesuai dengan karakteristik pembelajaran PKn. Selain menjadi tenaga pengajar, guru PKn juga diharapkan dapat menjadi tauladan yang baik bagi peserta didiknya, dapat memperbaiki moral siswa dan mampu mengurangi dampak globalisasi pada siswa. Hal ini dikarenakan PKn merupakan pendidikan yang mengajarkan tentang bagaimana rakyat Indonesia harus memiliki wawasan kebangsaan dan cinta tanah air terhadap Negara Indonesia. Penelitian ini menggunakan teknik penelitian kualitatif. Pengumpulan data diperoleh dengan teknik observasi, wawancara dan dokumentasi. Kemudian data tersebut dianalisis secara deskriptif analisis. Teknik keabsahan data dengan kredibilitas, transferabilitas, dependabilitas, dan konfirmabilitas. Guru PKn sudah mampu untuk meningkatkan wangsa cita siswa di SMA Muhammadiyah 1 Malang. Hal ini terbukti dari sikap siswa yang disiplin, patuh pada guru dan aturan sekolah, serta jujur meskipun belum seluruh siswa yang memiliki wangsa cita tersebut. Namun demikian meningkatkan wangsa cita siswa tidak terlepas dari hambatan yang ada seperti, tidak semua siswa yang mematuh peraturan sekolah dengan baik, dan tidak semua siswa memiliki wangsa cita yang baik pula, khususnya terkait pada era globalisasi yang ada saat ini. Solusi dalam menyikapi hambatan tersebut adalah mengajak ikut serta semua guru di SMA Muhammadiyah 1 Malang untuk dapat meningkatkan wangsa cita pada siswa, memanggil siswa yang bermasalah kekantor untuk dibina agar dapat dinasehati dan diberi pengarahan tentang wangsa cita pada dirinya. Selain solusi tersebut guru PKn beserta guru-guru yang lain harus lebih sabar dalam menghadapi siswa.
\end{abstract}

Kata Kunci : Wangsa Cita, Wawasan Kebangsaan, Cinta Tanah Air, Peranan Guru PKn.

\begin{abstract}
The concept of Nasionalism and patriotism give mean to an understanding, a ware nessand attitude as thechildren'selement thenation against thepillars of national life and make the orientation, value of realization and everyday behavior. As the role of civics teacher, educational of patriotism can grow and increase in children , because the Civics teacher is someone who should have the ability to manage the learning of students with the characteristics of civics lesson. In addition to being a teacher, civics teachers are also expected to be the good models for their students, they can improve students' morale and were able to reduce the impact of globalization on the students. Civics is a subject that teaches about how the people of Indonesia should have the nationalism and patriotism towardIndonesia. This study is a qualitative research. The data obtained by observation, interview and documentation. Then the data were analyzed descriptively.The validity of
\end{abstract}


The data were using the state of credibility, transferability, dependability, and conformability. The civics teachers have been able to increase the wangsacita of students in SMA Muhammadiyah 1 Malang. This was seen as the attitude of the students were disciplined, obedient to the teachers and school rules and being honest even though some of them haven't got the wangsa citayet. Nevertheless, in improving students' wangsacita cannot be separated from the existing obstacles such as not all of the students obey the school rules, and not all of the students have the good manner of wangsacita, especiallyin the era of globalization today. The solution in facing these obstacles all the teachers in SMA Muhammadiyah 1 Malang are invited to participate in improving the wangsacita towards the students, calling the troubled students to the office in order to be advised and briefed on the wangsacitaon them. In addition, the Civics teachers along with other teachers should be more patient in dealing with the students.

Keywords: Wangsa Cita, Nasionalism, Patriotism, The Role of Civics Teachers.

\section{PENDAHULUAN}

Jika mendengar kata "Globalisasi”, maka di dalam pemikiran mengatakan bahwa globaisasi merupakan kata yang sangat mengerikan dengan makna yang kabur, pertama kali dipakai pada tahun 1960-an, dan menjadi mode yang makin popular pada tahun 1990-an. Dimana mana orang mengatakan bahwa sekarang hidup dalam zaman dengan kehidupan sosial yang sebagian besar ditentukan oleh proses global, dalam zaman dimana garisgaris batas budaya nasional, ekonomi nasional dan wilayah nasional semakin kabur.

Menurut Hirst (2001: 3) asal katanya, kata "globalisasi” diambil dari kata global, yang maknanya ialah universal. Achmad Suparman menyatakan Globalisasi adalah suatu proses menjadikan sesuatu (benda atau perilaku) sebagai ciri dari setiap individu di dunia ini tanpa dibatasi oleh wilayah. Globalisasi belum memiliki definisi yang mapan, kecuali sekedar definisi kerja (workingdefinition), sehingga bergantung dari sisi mana orang melihatnya. Ada yang memandangnya sebagai suatu proses sosial, atau proses sejarah, atau proses alamiah yang akan membawa seluruh bangsa dan negara di dunia makin terikat satu sama lain, mewujudkan satu tatanan kehidupan baru atau kesatuan ko-eksistensi dengan menyingkirkan batas-batas geografis, ekonomi dan budaya masyarakat.

Indonesia adalah Negara Kesatuan yang memiliki identitas nasional yaitu Undang Undang Dasar 1945 sebagai konstitusi Negara Indonesia, Pancasila sebagai ideologi bangsa, bahasa Indonesia sebagai bahasa persatuan, beragam budaya nasional, lagu kebangsaan Indonesia Raya, 17 agustus 1945 sebagai hari lahirnya Negara Indonesia, lambang Negara yakni Burung garuda, yang semuanya tidak dapat dipisahkan dari jati diri Negara Indonesia. Identitas nasional harus diperjuangkan dan dicintai oleh seluruh rakyat Indonesia. Menjunjung tinggi tanah air Indonesia adalah kewajiban rakyat Indonesia sebagai bentuk kecintaan pada bangsa dan sebagai perwujudan sikap nasionalisme Indonesia aagar terhindar dari dampak globalisasi.

Menurut Amin (2014:2), dampak buruk globalisasi yang membawa kebudayaan baru menjadikan komposisi kebudayaan masyarakat Indonesia menjadi lebih kompleks atau rumit. Karena kebanyakan kebudayaan baru yang datang dan diterima begitu saja, menyebabkan terjadinya penyimpangan kebudayaan di masyarakat. Belum lagi masalah klasik 
yang sepele namun berdampak serius seperti perbedaan suku, agama, ras daan antar golongan yang semakin memecah belah persatuan dan kesatuan bangsa Indonesia.

Melihat kondisi tersebut, pendidikan wawasan kebangsaan harus dimiliki oleh seluruh rakyat Indonesia khususnya para generasi muda penerus bangsa. Seperti yang dinyatakan oleh Amin (2014:2) membangun anak-anak bangsa Indonesia dan kepribadian bangsa diperlukan satu usaha, salah satunya yaitu melalui pendidikan secara nasional. Tujuan yang hendak dicapai melalui pendidikan secara nasional antara lain bahwa pendidikan nasional harus mampu menumbuhkan dan memperdalam rasa cinta tanah air dengan kemajemukan dan keberagaman yang ada di Indonesia, mempertebal semangat kebangsaan, dan rasa kesatuan dan persatuan berbangsa dan bernegara. Melalui pendidikan juga diharapkan dapat menjadi wahana untuk melakukan pembentukan wawasan dan karakter bangsa, dan memperkuat komitmen kebangsaan menuju kehidupan berkualitas dan bermartabat.

Sejauh ini upaya yang telah dilakukan pemerintah adalah membangun Wawasan Kebangsaan melalui jalur pendidikan dengan diberikannya Pendidikan Kewarganegaraan (PKn) sebagai mata pelajaran pembentuk karakter. Dalam Undang-Undang Republik Indonesia No.20 tahun 2003 tentang Sistem Pendidikan Nasional, pasal 1 ayat 2 dikatakan bahwa Pendidikan nasional adalah pendidikan yang berdasarkan Pancasila dan Undang-Undang Dasar Negara Republik Indonesia Tahun 1945 yang berakar pada nilai-nilai agama, kebudayaan nasional Indonesia dan tanggap terhadap perubahan zaman.
Dalam pasal 37 dikatakan bahwa : Kurikulum pendidikan dasar dan menengah salah satunya wajib memuat PKn. Menurut Agung (2014), Tujuan Pendidikan PKn ialah mendidik warga Negara yang baik, yakni: (1) peka terhadap informasi baru yang dijadikan pengetahuan dalam kehidupannya; (2) warga negara yang berketerampilan; (a) peka dalam menyerap informasi; (b) mengorganisasi dan menggunakan informasi; (c) membina pola hubungan interpersonal dan partisipasi sosial; (3) warga negara yang memiliki komitmen terhadap nilai - nilai demokrasi, yang disyaratkan dalam membangun satu tatanan masyarakat yang demokratis dan beradap.

Melihat keadaan yang terjadi di Indonesia saat ini, kurangnya pemahaman masyarakat dan generasi muda terhadap pentingnya pendidikan wawasan kebangsaan dan cinta tanah air menjadi masalah yang dianggap penting untuk dibahas dalam penelitian ini,di SMA Muhammadiyah 1 Malang ini peneliti menemukan banyak sekali prilaku dari para siswanya yang sangat mengikuti kebudayaan masa kini baik itu dari cara berbicara atau cara berpakaiannya, ada beberapa siswa yang peneliti temukan mem-bully temannya yang berbeda suku dengannya sehingga temannya tersebut dijahui dan tidak diajak berteman. Kejadian diatas hanyalah sebagian kecil contoh yang peneliti perhatikan di SMA 1 Muhammadiyah Malang tersebut.

Menurut Diana (2015: 4) masa depan bangsa Indonesia sangatlah ditentukan oleh generasi muda terdidik ini. Siswa seharusnya menjadi generasi yang banyak mendapatkan berbagai pengetahuan teoritik maupun praktis di sekolah tentang tema-tema pembangunan bangsa sesuai pada kompetensinya masing-masing.

Eka Nur, dkk. Peranan Guru PKn dalam Meningkatkan Wawasan Kebangsaan dan Cinta Tanah Air (Wangsa Cita) di Era Globalisasi Pada Siswa Sma Muhammadiyah 1 Malang 
Sebagai generasi masa depan, kiranya penting pula mempersiapkan siswa dengan berbagai pola pendidikan yang mampu menanamkan pendidikan wawasan kebangsaan. Agar tercapainya pendidikan wawasan kebangsaan tersebut bidang studi yang sangat memegang peran penting untuk pencapaian tersebut adalah mata pelajaran PKn yang telah diajarkan disemua jenjang pendidikan mulai dari tingkat taman kanakkanak sampai dengan perguruan tinggi, baik pendidikan negeri maupun swasta. Oleh karena itu guru yang memegang mata pelajaran PKn lah yang menjadi sorotan utama keberhasilan penanaman pendidikan wawasan kebangsaan kepada para siswanya. Oleh karena itu berdasarkan uraian latar belakang masalah dan identifikasi permasalahan di atas, maka peneliti dalam penelitian ini tertarik untuk mengambil judul "Peranan Guru PKn Dalam Meningkatkan Wawasan Kebangsaan dan Cinta Tanah Air (Wangsa Cita) di Era Globalisasi Pada Siswa SMA Muhammadiyah 1 Malang”.

Berdasarkan latar belakang masalah, maka rumusan masalah dalam penelitian ini adalah sebagai berikut:

a) Bagaimanakah kondisi wangsa cita siswa di SMA 1 Muhammadiyah Malang di era globalisasi ini?

b) Bagaimanakah peranan guru PKn dalam meningkatkan pendidikan wangsa cita pada siswa di SMA 1 Muhammadiyah Malang dalam menghadapi tantangan globalisasi?

c) Apakah faktor pendukung dan penghambat peran guru PKn dalam peningkatan wangsa cita siswa di SMA Muhammadiyah 1 Malang?

d) Bagaimana solusi untuk mengatasi hambatan yang terjadi pada wangsa cita siswa di SMA Muhammadiyah 1 Malang?

\section{METODE}

Penelitian ini menggunakan penelitian kualitatif karena permasalahan yang menjadi pusat penelitian ini tidak berkenaan dengan angka-angka atau hitungan, melainkan mendeskripsikan, menggambarkan serta menguraikan tentang peranan guru PKn dalam meningkatkan pendidikan wawasan kebangsaan dan cinta tanah air (wangsa cita) siswa SMA Muhammadiyah 1 Malang untuk menghadapi tantangan globalisasi. Tujuan dari penelitian kualitatif ini adalah agar peneliti serta pembaca dapat mengetahui, menggambarkan, mengungkapkan (do describe and explore), dan menggabarkan, menjelaskan (do describe and explain).

Penelitian kualitatif memerlukan ketajaman analisis, objektivitas, sistematis, dan sistematik sehingga diperoleh ketepatan dalam interpretasi, sebab hakikat dari satu fenomena atau gejala penganut penelitian kualitatif adalah totalitas atau gestalt (Zuriah,2009:92). Menurut Lofland dan Lofland (dalam Moleong : 2012:157) sumber data utama dalam penelitian kualitatif adalah kata-kata, dan tindakan, selebihnya adalah data tambahan seperti dokumen dan lain-lain. Berkaitan dengan hal itu pada bagian ini jenis datanya dibagi kedalam kata-kata dan tindakan, sumber data tertulis, foto, dan statistik. Adapun jenis pendekatan penelitian ini adalah deskriptif, penelitian deskriptif yaitu peneitian yang berusaha untuk menuturkan pemecahan masalah yang ada sekarang berdasarkan dara-data.

Penelitian dilakukan di SMA Muhammadiyah 1 Malang. Alasan mengapa saya mengambil tempat ini karena berdasarkan keadaan yang ada, banyak prilaku peserta didik yang tidak mencerminkan prilaku wawasan 
kebangsaan dan cinta tanah air serta banyaknya peserta didik yang mengikuti arus globalisasi tanpa bisa meminimalisirnya seperti penggunaan handphone diruangan kelas ketika guru sedang menerangkan. Waktu penyusunan proposal ini dimulai pada Oktober sampai dengan bulan November 2015. Sedangkan waktu penelitian akan dilaksanakan pada Januari sampai akhir Febuari 2016.

\section{HASIL DAN PEMBAHASAN}

Kegiatan penelitian yang dilakukan oleh peneliti di SMA Muhammadiyah 1 Malang, diperoleh hasil penelitian mengenai peranan guru PKn dalam meningkatkan wangsa cita pada siswa SMA Muhammadiyah 1 Malang di era globalisasi ini adalah sebagai berikut:

\section{Kondisi Wawasan Kebangsaan Siswa SMA Muhammadiyah 1 Malang di Era Globalisasi}

Berdasarkan wawancara tentang peranan guru PKn dalam meningkatkan wangsa cita di SMA Muhammadiyah 1 Malang diperoleh kesimpulan bahwa kondisi wangsa cita siswa SMA Muhammadiyah 1 Malang telah baik. Setiap siswa SMA Muhammadiyah 1 Malang di dalam dirinya sudah tertanam rasa wangsa cita sejak lahir dan siswa juga menerapkannya dalam bentuk sikap sehari-hari. Contohnya seperti siswa yang setiap hari senin melakukan kegiatan Upacara Bendera, setelah itu setiap hari dari jam 06.45-07.00 WIB melakukan sholat dhuha berjama'ah, mentaati peraturan sekolah yang berlaku, jika ada yang melanggar peraturan sekolah sekolah dengan langsung memberikan hukuman berupa menyanyikan lagu nasional sehingga siswa seraca tidak langsung diharapkan menghafalkan lagu-lagu nasional tersebut, siswa mengikuti pembelajaran PKn yang diajarkan oleh guru PKn dengan materi wangsa cita dan diberikan tugas, lalu mereka mempresentasikannya dengan baik di depan kelas, hal tersebut merupakan salah satu contoh bahwa siswa SMA Muhammadiyah 1 Malang memiliki kondisi wangsa cita yang sangat baik.

Oleh karena kondisi wangsa cita yang dimiliki oleh siswa SMA Muhammadiyah 1 Malang ini sangat baik, hal ini memberikan dampak positif bagi diri siswa itu sendiri, bagi guru yang mengajarkan dan bagi lingkungan sekitar siswa. Kondisi wangsa cita siswa SMA Muhammadiyah 1 Malang ini juga dapat dibuktikan dari antusias mereka mengikuti berbagai macam lomba tari daerah untuk memperkenalkan kesenian daerah kepada rakyat Indonesia agar tidak ada lagi kesenian Indonesia yang di cap menjadi milik negara luar. Menumbuhkan wangsa cita kepada siswa SMA Muhammadiyah 1 Malang juga dilakukan melalu mata pembelajaran PKn oleh Guru PKn, meskipun tidak hanya sekedar guru PKn saja yang berperan dalam meningkatkan wangsa cita siswa, namun guru Pkn dalam menyampaikan materi wangsa cita memberikan sarana yang baik dalam meningkatkan wangsa cita siswanya.

\section{Peranan Guru PKn dalam Meningkatkan Wangsa Cita Siswa SMA Muhammadiyah 1 Malang}

Wawasan kebangsaan siswa SMA Muhammadiyah 1 Malang memang telah baik keberadaannya walaupun tidak semua siswa memiliki wangsa cita yang baik. Namun peran guru Pkn dalam meningkatkan wangsa cita yang sudah ada pada siswa SMA Muhammadiyah 1 Malang juga tidak kalah pentingnya. Sebagai tenaga pengajar, guru Pkn berperan untuk memberikan informasiinformasi berupa pengetahuan baru tentang

Eka Nur, dkk. Peranan Guru PKn dalam Meningkatkan Wawasan Kebangsaan dan Cinta Tanah Air (Wangsa Cita) di Era Globalisasi Pada Siswa Sma Muhammadiyah 1 Malang 
wangsa cita, menjelaskan tentang dampak yang akan ditimbulkan jika seseorang tidak menanamkan wangsa cita itu sejak dini. Guru Pkn juga dalam setiap menjelaskan materi selalu menyisipkan pengetahuanpengetahuan yang berhubungan dengan wangsa cita bangsa sehingga siswa SMA Muhamammadiyah 1 Malang selalu mengingat pentingnya meningkatkan wangsa cita tersebut. Guru Pkn dapat memotivasi siswa agar tidak terjerumus kepada dampak dari era globalisasi seperti sekarang ini. Ketika memulai pelajaran, guru PKn selalu melihat keadaan kelas sudah rapi atau belum, guru PKn juga selalu memberikan kesempatan kepada siswa SMA Muhammadiyah 1 Malang untuk menyampaikan pendapatnya dengan sopan di depan kelas. Ketika ada yang melanggar di dalam kelas, hukuman andalan yang dilakukan guru PKn adalah dengan cara siswa diminta untuk menyanyikan 10 lagu wajib. Hal ini tidak semata-mata hanya menghukum saja, makna yang terkandung didalamnya adalah agar siswa selalu menjunjung negara Indonesia, dan selalu menerapkan wangsa cita pada kehidupan sehari-hari. Peran guru PKn diluar kelas contohnya adalah sebagai guru piket. Dalam menjalankan piketnya guru PKn selalu memberikan pelajaran-pelajaran berharga berupa wangsa cita. Sama seperti di dalam kelas, ketika guru PKn bertugas sebagai guru piket dan ada siswa yang melanggar, maka guru PKn beserta guru piket yang lain memberikan hukumanhukuman yang dapat membangun wangsa cita siswa.

\section{Faktor Pendukung dan Faktor Penghambat peranan guru PKn dalam Meningkatkan Wangsa Cita}

Meningkatkan wangsa cita pada siswa SMA Muhammadiyah 1 Malang memanglah tidak mudah, oleh karena itu dibutuhkan metode-metode sebagai penunjang dalam meningkatkan wangsa cita siswa SMA Muhammadiyah 1 Malang. Faktor pendukung salah satunya adalah adanya peraturan sekolah tentang tata tertib yang wajib dipatuhi oleh siswa SMA Muhammadiyah 1 Malang. Tidak hanya itu, guru Pkn memiliki kreativitas yang tinggi sehingga sangat dapat meminimalisir tidak tercapainya wangsa cita pada peserta didik. Faktor pendukung lainnya adalah guru-guru yang lain yang senantiasa membantu guru Pkn dalam meningkatkan wangsa cita.

Tidak hanya faktor pendukung, namun dalam pelaksanaan penerapan wangsa cita oleh peran guru PKn tersebut juga mengalami faktor penghambat. Salah satunya adalah dari dalam diri siswa (internal) maupun dari luar diri siswa itu sendiri (eksternal). Dari dalam diri siswa berupa adanya ketiaksamaan presepsi antara guru Pkn dan siswa SMA Muhammadiyah 1 Malang tentang materi yang diajarkan yaitu wangsa cita, sehingga siswa terkesan cuek dan tidak mendengarkan apa yang dijelaskan oleh guru PKn. Ketika siswa tidak mendengarkan materi yang disampaikan berarti siswa tersebut tidak mendapatkan ilmu pengetahuan bagaimana pentingnya wangsa cita bagi siswa di era globalisasi seperti ini. Sedangkan faktor penghambat dari luar diri siswa itu berupa faktor lingkungan sekitar siswa baik disekolah maupun diluar sekolah dan dari wali siswa itu sendiri. Untuk meningkatkan wangsa cita pada siswa SMA Muhammadiyah 1 Malang tidak semata-mata hanya guru PKn dan guru-guru disekolah saja yang berperan. Percuma ketika disekolah siswa diajarkan bagaimana pentingnya wangsa cita bagi diri sendiri dan bangsa apabila lingkungan teman, lingkungan tempat tinggal dan wali 
siswanya sendiri tidak mendukung untuk meningkatkan wangsa cita siswa di SMA Muhammadiyah 1 Malang.

\section{Solusi Untuk Mengatasi Hambatan yang Terjadi pada Wangsa Cita Siswa SMA Muhammadiyah 1 Malang}

Setiap masalah yang dihadapi pastilah dapat diatasi dengan berbagai macam solusi . begitu pula dengan faktor penghambat dalam peranan guru $\mathrm{PKn}$ dalam meningkatkan wangsa cita di SMA Muhammadiyah 1 Malang ini. Solusi untuk mengatasi kendala tersebut dapat dilakukan dengan cara mengajak ikut serta semua guru di SMA Muhammadiyah 1 Malang untuk dapat meningkatkan wangsa cita pada siswa SMA Muhammadiyah 1 Malang. Memanggil siswa yang bermasalah kekantor untuk dibina agar dapat dinasehati dan dapat ditingkatkan kembali wangsa cita pada dirinya. Hal ini dapat disimpulkan bahwa memberikan pemahaman tentang bagaimana pentingnya wawasan kebangsaan pada peserta didik itu sangatlah penting, apalagi pada siswa yang bisa dianggap bandel atau nakal. Hal ini dilakukan guru semata-mata hanyalah untuk memperbaiki karakter siswa tersebut agar tidak mudah terjerumus kepada perilakuperilaku menyimpang di era globalisasi seperti ini.

Selain solusi tersebut guru PKn beserta guru mata pelajaran yang lain harus lebih sabar dalam mengahadapi siswa, setidaknya memberikan contoh yang baik bagaimana pentingnya wangsa cita bagi diri sendiri dan bangsa Indonesia.

\section{SIMPULAN}

Berdasarkan hasil penelitian yang mengacu pada rumusan masalah peneliti dan tujuan penelitian tentang peranan guru PKn dalam meningkatkan wawasan kebangsaan dan cinta tanah air (wangsa cita) di era globalisasi pada siswa SMA Muhamammadiyah 1 Malang dapat disimpulkan bahwa :

1. Berdasarkan wawancara kepada beberapa informan dapat disimpulkan bahwa kondisi wangsa cita siswa SMA Muhammadiyah 1 Malang telah baik. Setiap siswa SMA Muhammadiyah 1 Malang di dalam dirinya sudah tertanam rasa wangsa cita sejak lahir dan siswa juga menerapkannya dalam bentuk sikap sehari-hari. Contohnya seperti siswa yang setiap hari senin melakukan kegiatan Upacara Bendera, setelah itu setia hari dari jam 06.4507.00 WIB melakukan sholat dluha berjama'ah, mentaati peraturan sekolah yang berlaku, jika ada yang melanggar peraturan sekolah, sekolah dengan langsung memberikan hukuman berupa menyanyikan lagu wajib sehingga siswa seraca tidak langsung diharapkan menghafalkan lagu-lagu nasional tersebut, siswa mengikuti pembelajaran PKn yang diajarkan oleh guru PKn dengan materi wangsa cita dan diberikan tugas, lalu mereka mempresentasikannya dengan baik di didepan kelas, hal tersebut merupakan salah satu contoh bahwa siswa SMA Muhammadiyah 1 Malang memiliki kondisi wangsa cita yang sangat baik. pendidikan wangsa cita itu sangat penting untuk dimiliki oleh siswa SMA Muhammadiyah 1 Malang sebagai generasi penerus bangsa karena dengan dimilikinya wangsa cita oleh siswa SMA Muhammadiyah 1 Malang, maka Negara Indonesia akan menjadi Negara yang tetap utuh, kuat dan bersatu sehingga NKRI tetap terjaga. Pada era globalisasi ini seperti wangsa cita sangat penting sebagai dasar kita sebagai peserta didik untuk menyaring apa dampak positif yang kita ambil dari globalisasi dan dapat

Eka Nur, dkk. Peranan Guru PKn dalam Meningkatkan Wawasan Kebangsaan dan Cinta Tanah Air (Wangsa Cita) di Era Globalisasi Pada Siswa Sma Muhammadiyah 1 Malang 
mengetahui dan mengurangi dampak negatif dari globalisasi itu.

2. Guru Pkn sangat berperan dalam meningkatkan wangsa cita siswa SMA Muhammadiyah 1 Malang. Guru PKn selain menjadi tenaga pengajar di SMA Muhammadiyah 1 Malang, Guru PKn juga dapat menjadi tauladan yang baik bagi peserta didiknya. Guru PKn mampu memperbaiki moral siswa dan mampu mengurangi dampak globalisasi pada siswanya. Salah satu contoh yang dilakukan guru PKn di luar kelas adalah dengan menjadi guru piket. Dalam tugasnya Mengenai guru piket, jika ada siswa yang terlambat dan tidak mengikuti peraturan sekolah, akan diberi efek jera berupa hukuman menyanyikan lagu wajib, menyanyikan lagu daerah dan membacakan pembukaan UUD 1945. Hal ini dilakukan agar siswa lebih mengenal dan mencintai Negara Indonesia sehingga siswa malu untuk melakukan pelanggaran lagi di sekolah. Sebagai tenaga pengajar, guru Pkn berperan untuk memberikan informasi-informasi berupa pengetahuan baru tentang wangsa cita, menjelakan tentang dampak yang akan ditimbulkan jika seseorang tidak menanamkan wangsa cita itu sejak dini. Guru Pkn juga dalam setiap menjelaskan materi selalu menyisipkan pengetahuan-pengetahuan yang berhubungan dengan wangsa cita bangsa sehingga siswa SMA Muhamammadiyah 1 Malang selalu mengingat pentingnya meningkatkan wangsa cita tersebut. Guru Pkn dapat memotivasi siswa agar tidak terjerumus kepada dampak dari era globalisasi seperti sekarang ini.

3. Faktor internal yang menghambat berjalannya peranan guru PKn dalam meningkatkan wangsa cita siswa seperti seorang siswa yang sangat sulit diubah dan membutuhkan waktu lama sangat menurunkan kinerja dan peranan Guru sebagai untuk meningkatkan wangsa cita peserta didiknya. Peserta didik yang malas untuk belajar, dan adanya perbedaan pendapat dan presepsi antara guru PKn dan siswa sehingga membuat siswa tidak enak untuk mengikuti pembelajaran sehingga siswa tidak mendengarkan pembelajaran terkesan seperti tidak menghargai guru merupakan faktor terbesar yang selama ini menghalangi peranan guru PKn dalam meningkatkan wawasan kebangsaan itu sendiri. Sedangkan faktor eksternalnya seperti wali murid yang terkesan acuh pada peserta didik dan lingkungan pergaulan peserta didik yang dianggap salah, sehingga pembelajaran wangsa cita yang telah diterangkan oleh guru PKn menjadi tidak dihiraukan.

4. Faktor pendukung dalam meningkatkan wangsa cita melalui peranan guru PKn salah satunya adalah adanya peraturan sekolah tentang tata tertib yang wajib dipatuhi oleh siswa SMA Muhammadiyah 1 Malang. Tidak hanya itu, guru Pkn memiliki kreativitas yang tinggi sehingga sangat dapat meminimalisir tidak tercapainya wangsa cita pada peserta didik. Faktor pendukung lainnya adalah guru-guru yang lain yang senantiasa membantu guru Pkn dalam meningkatkan wangsa cita.

5. Solusi untuk mengatasi kendala dalam peranan guru PKn dalam meningkatkan wangsa cita tersebut dapat dilakukan dengan cara mengajak ikut serta semua guru di SMA Muhammadiyah 1 Malang untuk dapat meningkatkan wangsa cita pada siswa SMA Muhammadiyah 1 Malang. Memanggil siswa yang 
bermasalah kekantor untuk dibina agar dapat dinasehati dan dapat ditingkatkan kembali wangsa cita pada dirinya. Selain solusi tersebut guru PKn beserta guru mata pelajaran yang lain harus lebih sabar dalam mengahadapi siswa, setidaknya memberikan contoh yang baik bagaimana pentingnya wangsa cita bagi diri sendiri dan bangsa Indonesia.

\section{DAFTAR PUSTAKA}

Agung, I,. 2014. Pendidikan Wawasan Kebangsaan Daerah Perbatasan. Jakarta : Penerbit Bee madia Pustaka. Amin, Muhammad. 2014. Peran Mata Kuliah PPKn dalam Pemumbuhan Semangat Bhinrka Tunggal Ika pada Mahasiswa Jurusan Civic Hukum Angkatan 2013 Universitas Muhammadiyah Malang.Skripsi. Malang: Fakultas Keguruan dan Ilmu Pendidikan, Universitas Muhammadiyah Malang.

Centre For Strategic And International Studies (CSIS). 1976. Pandangan Presiden Soehato Tentang Pancasila. Jakarta: Yayasan Proklamasi Centre For Strategic And International Studies (CSIS).

Diana, Ajeng. 2015. Penumbuhan Semangat Nasionalisme pada Siswa SMKN 13 Malang Melalui Mata Pelajaran PPKn. Skripsi. Malang: Fakultas Keguruan dan Ilmu Pendidikan, Universitas Muhammadiyah Malang.

Hirst, P., Thompson,G.. 2001.Globalisasi Adalah Mitos. Jakarta: Yayasan Obor Indonesia.

Moleong, Lexy J,. 2012. Metode Penelitian Kualitatif Edisi Revisi. Bandung: PT. Remaja Rosdakarya.
Zuriah, Nurul. 2009. Metodelogi Penelitian Sosial dan Pendidikan Teori-Aplikasi. Jakarta: Bumi Aksara 